\title{
Effective Methods of Grain Fine Structure of Aluminum Alloys
}

\author{
Irina G. Brodova* \\ Institute of Metal Physic Ural Branch of RAS \\ 18 S. Kovalevskay, Ekateriburg, 620990, Russia
}

Received 20.02.2015, received in revised form 29.03.2015, accepted 24.05.2015

\begin{abstract}
Experimental results on the creation of fine-grained aluminum alloys with different scale structural components, ranging from tens of microns to tens of nanometers, by various external influences in the liquid and solid states were present. It is found that complex processing of the melt, including its heating to a temperature corresponding to the point on the hysteresis of the toughness poluterms and rapid quenching at a rate not less than $1000 \mathrm{~K} / \mathrm{s}$ result in fine-grained structure in cast alloys with transition metals. New master alloys with high doping and modifying abilities, due to the formation in their structures metastable dispersed zirconium or titanium aluminides or nanoparticles of titanium carbide were offered. The regularities of formation of industrial submicrocrystalline alloys by new method of high-speed plastic deformation - the dynamic channel-angular pressing and nanostructured alloys by torsion in Bridgman anvils were studied.
\end{abstract}

Keywords: Aluminum alloys, fine-grained structure, master alloys, melt rapid quenching, high-speed plastic deformation.

\section{Эффективные способы измельчения}

\section{структуры алюминиевых сплавов}

И.Г. Бродова

Институт физики металлов УрО РАН

Россия, 620990, Екатеринбург, ул. С. Ковалевской, 18

Представлены экспериментальные результаты по созданию мелкокристаллических алюминиевых сплавов с разным масштабом структурных составляюших, от десятков микрон до десятков нанометров, путём различных внешних воздействий в жидком и твёрдом состояниях. Установлено, что комплексная обработка расплава, включающая его нагрев до температуры, соответствующей точке гистерезиса на политерме вязкости, и быстрая закалка со скоростью не менее $1000 \mathrm{~K} / \mathrm{c}$ приводят к получению мелкокристаллической структуры в литых сплавах с переходными металлами. Предложены новые лигатурные

(c) Siberian Federal University. All rights reserved

* Corresponding author E-mail address: brodova@imp.uran.ru 
сплавы, обладающие высокой легирующей и модифицирующей способностью за счёт формирования в их структуре дисперсных метастабильных алюминидов ичиркония или титана, а также наночастии карбида титана. Исследованы закономерности формирования субмикрокристаллических сплавов новым методом высокоскоростной пластической деформации - динамическим канально-угловым прессованием и наноструктурных сплавов методом кручения в наковальнях Бриджмена.

Ключевые слова: алюминиевые сплавы, модифицированная структура, лигатуры, быстрая закалка, интенсивная пластическая деформация.

\section{Введение}

Алюминиевые сплавы с тугоплавкими металлами (TM - Ti, $\mathrm{Cr}, \mathrm{Fe}, \mathrm{Mn}, \mathrm{Zr}$ ) занимают особое место среди сплавов на основе $\mathrm{Al}$ за счет ряда своих особенностей [1]. В частности, небольшие добавки Ті в количестве до $0,15 \%^{1}$ вводят в деформируемые и литейные сплавы для измельчения зерна. Цирконий является сильным антирекристаллизатором. Дисперсоиды алюминидов ТМ, выделяющиеся при распаде пересыщенного алюминиевого раствора, увеличивают прочность и замедляют процессы роста зёрен [2]. Из-за низкого коэффициента диффузии ТМ в алюминиевой матрице образование сильно пересыщенных твердых растворов затруднено и в сплавах, содержащих 1-8 \% ТМ, возможно только при быстрой закалке расплава. Такие композиции служат основой гранулируемых сплавов [2]. Кроме того, сплавы с повышенным содержанием ТМ используют в качестве тугоплавких лигатур при производстве литейных и деформированных сплавов [3]. Замена традиционных лигатурных сплавов на основе алюминия с тугоплавкими компонентами на аналогичные по составу, но обладающие более высокой модифицирующей способностью является важной проблемой для всей металлургической отрасли, связанной с производством промышленных Al-сплавов. В качестве одного из способов регулирования структуры и свойств этих материалов можно применять температурно-временную обработку (ТВО) жидких сплавов в сочетании с быстрой закалкой расплава [4].

В настоящее время для измельчения зерен $\mathrm{Al}$ сплавов широко применяют методы интенсивной пластической деформации (ИПД), например РКУП [5]. Многочисленные работы в этой области показали их эффективность и широкий диапазон материалов, в которых создание микро-, субмикро- и наноструктур привело к существенному изменению физических и механических характеристик $[5,6]$.

Цель данной работы - изучить различные способы создания мелкокристаллических $\mathrm{Al}$ сплавов с разным масштабом структурных составляющих и повышенными эксплуатационными свойствами, используя специфические свойства этих материалов в жидком и твердом состояниях.

\section{Материалы и методы}

В качестве материалов исследования использовали бинарные и тройные композиции на основе $\mathrm{Al}$ с TM (Fe, $\mathrm{Zr}, \mathrm{Ti}, \mathrm{Cr}, \mathrm{Sc}, \mathrm{Mn})$, которые синтезировали в лабораторных условиях путем плавки под флюсом в шахтной печи и разливки в стальной кокиль (скорость охлаждения расплава $\left.v=100{ }^{\circ} \mathrm{C} / \mathrm{s}\right)$. Быстрая закалка расплава осуществлялась центробежным литьем в щеле-

$$
-520-
$$


вой медный кристаллизатор $\left(v=10^{3}-10^{4} \mathrm{C} / \mathrm{s}\right)$. Образцы имели форму дисков диаметром 80 мм и толщиной 1.0-0.6 мм. Температуры литья выбирали в зависимости от режимов ТВО расплава. Перегрев расплава выше соответствующих температур ликвидуса $\Delta \mathrm{t}=100-450{ }^{\circ} \mathrm{C}$.

Для изучения фазовых и структурных превращений в условиях пластической деформации применяли два метода: метод динамического канально-углового прессования - ДКУП [7] и метод кручения под высоким квазигидростатическим давлением (КГД).

КГД быстрозакристаллизованных образцов диаметром 10 мм проводили в наковальнях Бриджмена со скоростью 1 об/мин при давлении $\mathrm{P}=5$ GPa и комнатной температуре. Степень деформации определяли числом оборотов наковальни (n), которые варьировали от 1 до 15. Такие условия нагружения обеспечивали истинную логарифмическую степень деформации e = 3.8-7.2. Метод ДКУП, в основе которого лежит схема равно-канального углового прессования, за счет энергии импульсных источников создаёт большие скорости деформации $10^{4}-10^{5} \mathrm{~s}^{-1}$. Высокая скорость деформации, специфическое напряженно-деформационное состояние, формирующееся в материале в процессе деформации вследствие сочетания ударной волны и механического сдвига, являются причиной быстрой кинетики формирования СМК структуры в материале. Заготовками для ДКУП² служили образцы диаметром 14-16 мм и длиной 60-65 мм, вырезанные из горячепрессованных прутков промышленных сплавов типа АМц и В95 в отожженном состоянии. Образцы были получены после одного и четырёх циклов прессования $(\mathrm{N}=1-4)$ при начальной скорости движения образцов, равной 80-300 м/с.

Металлографические исследования образцов выполнены с помощью оптических микроскопов «МБС-9» и «Neophot-32». Количественные характеристики структурных компонентов сплава определяли с использованием стандартных методик. Измерение параметра решетки и

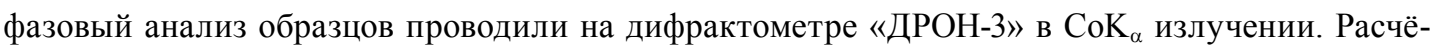
ты осуществляли с помощью пакета программ «Profile». Электронно-микроскопические исследования выполняли на электронном просвечивающем микроскопах JEM-200CX и Philips CM-30. Размеры структурных составляющих деформированных образцов рассчитывали по темнопольным электронно-микроскопическим снимкам с помощью компьютерной программы «Siams-700». Для определения химического состава и морфологии структурных составляющих использовали сканирующий электронный микроскоп «Quanta-200» с приставкой EDAX. Микротвердость $\mathrm{H}_{\mathrm{V}}$ измеряли на приборе ПМТ-3 при нагрузке $0.2 \mathrm{~N}$ (погрешность не превышала 10 \%). Механические свойства определяли по стандартным методикам на машине ZWICK/ Roell Z050.

\section{Результаты и их обсуждение}

\section{Температурно-временная обработка и быстрая закалка расплава}

Опираясь на экспериментальные данные структурно-чувствительных свойств жидких Al-TM сплавов (кинематическую вязкость и плотность), разработали режимы ТВО расплавов, которые позволили варьировать структуру быстрозакристаллизованных сплавов заэвтектического (Al-Fe, Al-Sc) и заперитектического (Al-Ti, Al-Zr, Al-Cr-Zr) составов в широких пределах [4]. Так, уже при кристаллизации со скоростями $10^{3}{ }^{\circ} \mathrm{C} / \mathrm{s}$ достигались большие переохлаждения расплава на фронте кристаллизации и формировались метастабильные структуры. В частности, аномально пересыщенные ТМ твердые растворы на основе Al, квазиэвтектики, метаста-

$$
-521-
$$


бильные алюминиды ТМ и т.д. [4]. Данные результаты были использованы для разработки лигатурных алюминиевых сплавов с тугоплавкими добавками [8].

\section{Лигатурные алюминиевые сплавы}

нового поколения с циирконием и титаном

Легирование и модифицирование лёгких сплавов тугоплавкими добавками является надёжным источником улучшения их структуры и повышения механических, физико-химических и эксплуатационных свойств. В настоящее время в заводской практике для этих целей применяют специальные $\mathrm{Al}$ лигатуры, содержащие до 5 wt. \% тугоплавкого компонента (Ti, $\mathrm{Zr}, \mathrm{Cr}$, $\mathrm{V}, \mathrm{Mn}, \mathrm{Mo} \mathrm{и} \mathrm{др.),} \mathrm{которые} \mathrm{представляют} \mathrm{собой} \mathrm{двух-} \mathrm{или} \mathrm{трёхфазные} \mathrm{композиции,} \mathrm{содержащие}$ алюминиды тугоплавких металлов. Введение этих лигатур в Al-расплавы требует тщательного подбора теплофизических параметров процесса плавки, в противном случае в структуре слитков и отливок формируются избыточные интерметаллиды и «веерные» кристаллы, которые сильно снижают качество литого материала и его технологическую пластичность и прочность.

Одним из решений такой важной проблемы в практике металлургического производства является замена традиционных лигатур на новые сплавы с высокой модифицирующей и легирующей способностью.

Оригинальность подхода к решению этой задачи в наших разработках заключается в использовании разных методов быстрой закалки расплава (кристаллизация в узкий щелевой медный кокиль, литьё гранул), обеспечивающих формирование двухфазной структуры лигатур, содержащей дисперсные метастабильные алюминиды циркония или титана. Наличие таких фаз с кубической решеткой типа $\mathrm{L}_{2}$ и быстрой кинетикой растворения в $\mathrm{Al}$ расплавах (вместо кристаллов с тетрагональной решёткой структурного типа $\mathrm{D} 0_{23}$ и $\mathrm{D} 0_{22}$ ) обеспечивает большое количество центров кристаллизации. Близкое структурное и размерное соответствие с решеткой алюминия и малые размеры интерметаллидов (1-2 мкм) оказывают сильный модифицирующий эффект и создают условия для образования мелкозернистой равномерной структуры отливок и слитков.

На рис. 1 показано сравнение структуры заводского лигатурного сплава Al-2 \% Zr, полученного литьём в чушку (рис. $1 a$ ), и опытной лигатуры, отлитой в щелевой кокиль (рис. $1 \sigma$ ).

Данные РСА показали, что интерметаллиды в опытной лигатуре являются метастабильной модификацией алюминида циркония с кубической решёткой в отличие от одноимённых интерметаллидов с тетрагональной решёткой $\mathrm{D} 0_{23}$ в заводской лигатуре и имеют размеры не более 3 мкм.

Для получения сплавов с метастабильными алюминидами в промышленном масштабе целесообразно применять метод литья гранул. Такую технологию удалось реализовать на ООО «УРАЛИНТЕХ», где на грануляторе «Induterm VC3000D» были получены гранулы из Al-сплавов, содержащих 1.7-10 \% циркония [8]. В процессе эксперимента варьировали температуру нагрева, размеры гранул и их химический состав. Было установлено, что в исследованном интервале температур нагрева расплава (от 1000 до $1350{ }^{\circ} \mathrm{C}$ ) и скорости охлаждения $1000{ }^{\circ} \mathrm{C} / \mathrm{s}$ формирование интерметаллидов метастабильной фазы наблюдается в сплавах, содержащих до $5 \%$ Zr. С ростом концентрации циркония до $10 \%$ при всех теплофизических условиях кристал- 


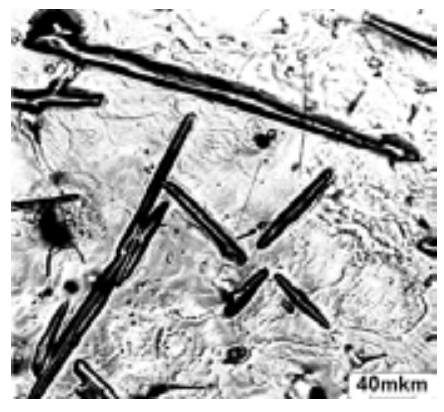

$\mathrm{a}$

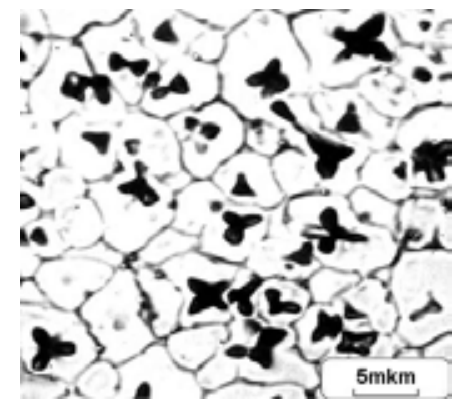

6

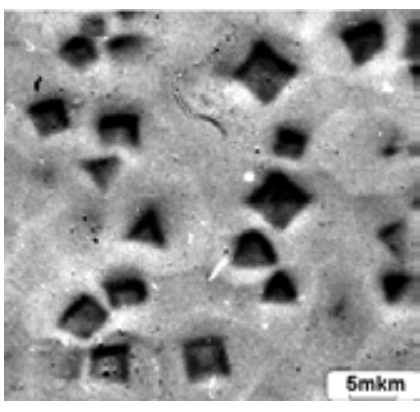

B

Рис. 1. Структура лигатурного сплава Al-2 \% Zr в зависимости от условий кристаллизации: $а$ чушку; б - литьё в щелевой кокиль; в - литьё гранул

лизации в гранулах образуются стабильные алюминиды с тетрагональной решеткой. Были построены зависимости размеров алюминидов от температуры расплава и размеров гранул и определены оптимальные условия литья, при которых формируются метастабильные фазы размером порядка микрона (рис. 1в).

Изготовленная опытная партия Al-Zr-гранул опробована в качестве лигатуры в заводских условиях. Проведенные на заводе опытные плавки по легированию слитков из сплава 1960 цирконием с помощью гранул состава Al-4 \% Zr показали 100\%-ное усвоение лигатуры алюминиевым расплавом. По данным проверки качества продукции в условиях завода в слитках и полуфабрикатах отсутствовали хрупкие алюминиды циркония, а количество циркония в матрице равнялось $0.2 \%$. Содержание неметаллических включений соответствовало ГОСТу.

Проведенные исследования показали, что для формирования метастабильных алюминидов в лигатурных Al-Ti сплавах необходимо повышать скорость кристаллизации до значений более $10^{4}{ }^{\circ} \mathrm{C} / \mathrm{s}$. Такие сплавы были получены в лабораторных условиях литьём в щелевой медный кокиль в виде тонких дисков или быстрой закалкой расплава на вращающийся диск в виде чешуек. Определены условия получения чешуек из сплава Al-4.5 \%Ті со структурой, содержащей метастабильную фазу $\mathrm{Al}_{3} \mathrm{Ti}\left(\mathrm{Ll}_{2}\right)$ размером не более 400 нм.

\section{Наноструктурированные модифицирующие лигатуры}

В ИФМ УрО РАН предложены разные технологии изготовления алюминиевых композитов, содержащих наноразмерные карбиды титана, в литом и деформированном состояниях. Эксперимент по получению литых наноструктурированных лигатурных сплавов включал в себя три этапа: синтез нанопорошков карбида методом механоактивации и их брикетирование, отработка методики введения брикетов в расплав алюминия и получение слитков лигатурных сплавов. Механоактивацию исходных порошков титана и графита с размерами от десятков до сотен микрон осуществляли в вибромельнице в среде аргона. В результате были получены порошки ТіС со средним размером 100 нм, которые прессовались с Al-порошком в брикеты [9]. Фазовый состав брикетов, определённый методом дифракционного рентгеноструктурного анализа, показал, что никаких посторонних фаз в процессе механосинтеза не образуется. 
Для улучшения смачиваемости нанопорошка, вводимого в Al-расплав, были опробованы различные варианты синтеза лигатурных сплавов. Применяли перемешивание расплава магнитным полем в низкочастотной $(10 \mathrm{KHz})$ индукционной печи, а также использовали обработку расплава низкочастотными колебаниями в режиме интенсивного перемешивания [10]. Колебания передавались в расплав через графитовый поршень-излучатель, который кроме основной функции удерживал брикеты от всплывания и контакта с воздушной средой. Металлографический анализ, выполненный с помощью сканирующего электронного микроскопа, показал, что наноразмерные и субмикронные карбиды титана в композите, полученном после обработки расплава низкочастотными колебаниями, равномерно распределены в алюминиевой матрице (светлые включения на рис. 2).

Опробованы различные варианты ввода нанопорошка $\mathrm{TiC}$ в расплав путём варьирования соотношения порошка $\mathrm{TiC}$ и $\mathrm{Al}$ в таблетках. Кроме того, рассмотрена возможность получения лигатурного сплава при замене порошка на гранулы ТiC, полученные путем двойного передела через состав $\mathrm{Al}_{30} \mathrm{TiC}_{70}$. Проведены специальные опыты по варьированию температуры ввода брикетов Al-TiC в расплав алюминия и его выдержки в индукционной печи до разливки в изложницу. Качество литого лигатурного сплава проверялось по однородности структуры, степени измельчения зерен матрицы и твердости слитка.

На рис. $3 a-2$ показана макроструктура лигатурных сплавов, содержащих от 0.12 до $1.0 \%$ $\mathrm{TiC}$, отличающихся способом приготовления шихты, содержащей нанопорошок карбида титана. При содержании ТіС менее 0.12 \% модифицирующий эффект отсутствует и наблюдается столбчатый характер кристаллизации (рис. $3 a$ ). Увеличение количества титана в композите от 0.2 (рис. 36,6 ) до $1.0 \%$ (рис. 32, $\partial$ ) приводит к закономерному измельчению зерна от 200-300 до 30 мкм.

В результате опробования разных вариантов синтеза лигатурных сплавов Al-TiC в индукционных печах на воздухе и в вакууме установлено, что наибольшая степень усвоения порошка $\mathrm{TiC}$ расплавом происходит, если использовать в качестве наноструктурированной шихты гранулы.

Проведено сравнение структуры опытной наноструктурированной лигатуры Al-TiC (рис. 2) и импортной лигатуры (Al-3 \%Ti-0.15\%C) компании «КBM AFFILIPS», в которой наряду с карбидной фазой присутствуют крупные пластинчатые кристаллы алюминида титана

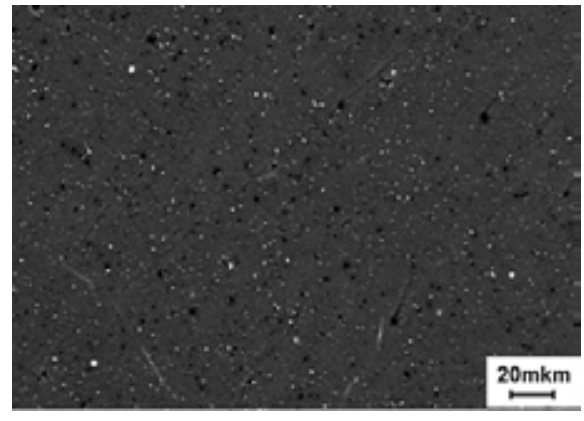

a

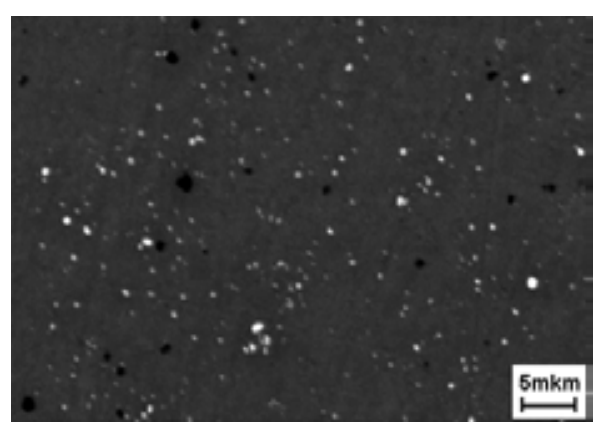

б

Рис. 2. Карбиды титана в композите Al-TiC (СЭМ) 


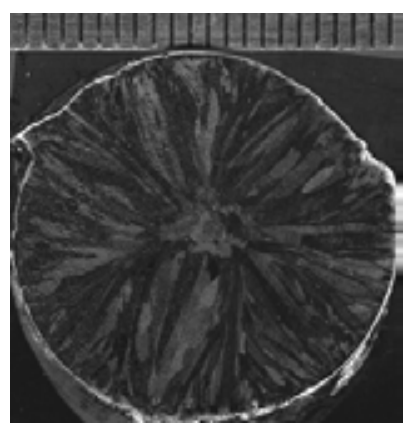

a

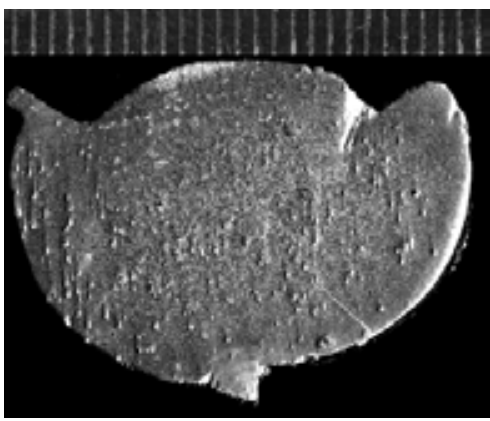

$\Gamma$

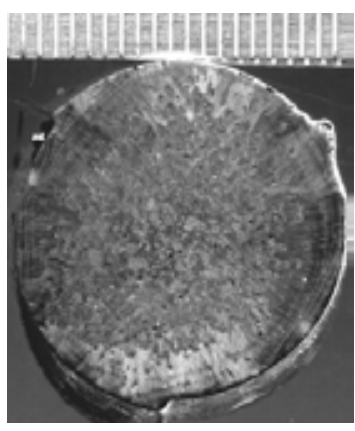

6

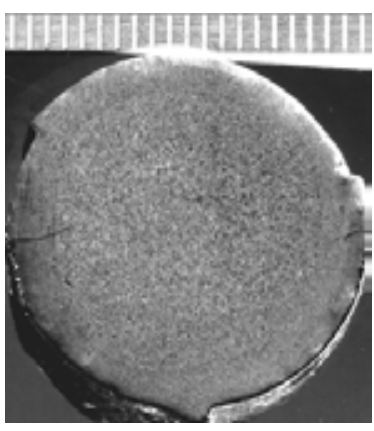

B

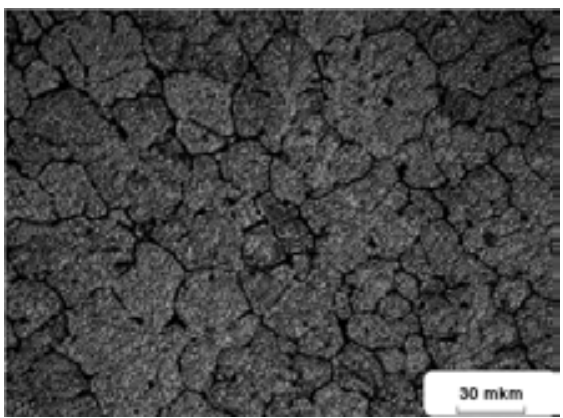

д

Рис. 3. Макроструктура слитков опытных лигатурных сплавов, полученных при разных способах ввода карбида титана: а, б - таблеткой; в - порошком, г, д - гранулами

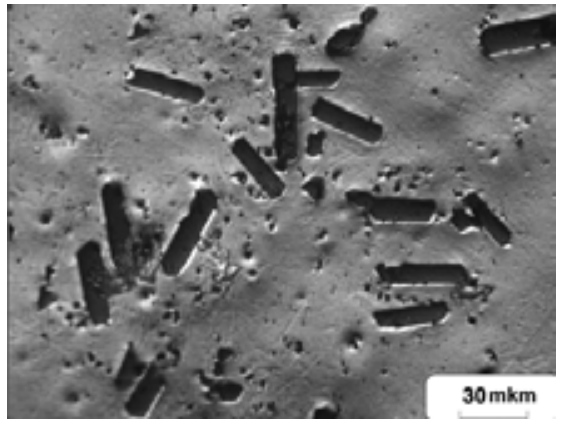

Рис. 4. Структура прутка серийного производства Al-3 \%Ті-0.15 \%C

(рис. 4). Установлено, что размер карбида ТiC в опытной лигатуре на порядок меньше, чем в импортном сплаве, а твердость в два раза выше. Данные характеристики служат важными критериями, определяющими эффективность зародышеобразования и модифицирующую способность лигатур.

На рис. 5 показано сравнение модифицирующих способностей двух лигатур на примере промышленного сплава $2024{ }^{3}$. Установлено, что в случае применения опытной лигатуры одинаковое измельчение зерна (60-80 мкм) наблюдается при уменьшенном в два раза содержании титана. 


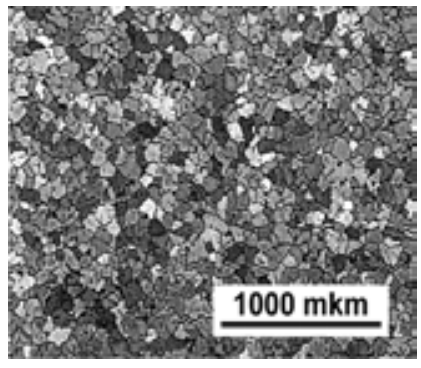

$a$

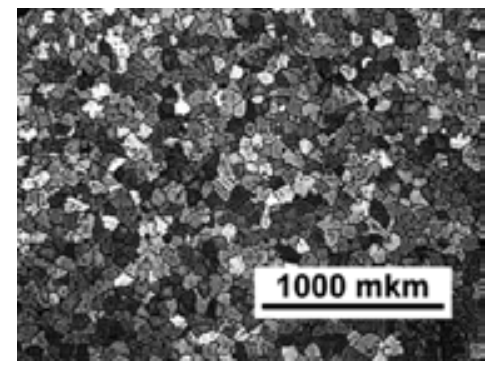

$\sigma$

Рис. 5. Сравнение структуры литого сплава 2024 после модифицирования: а - импортной лигатурой $(\mathrm{Ti}=0.016$ wt. \%); б - наноструктурной опытной лигатурой $(\mathrm{Ti}=0.008$ wt. \%)

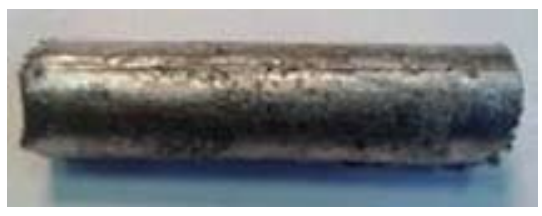

$a$

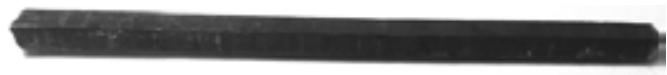

6

Рис. 6. Опытная лигатура Al-TiC в виде слитка (а) и в виде прутка (б)

Для изготовления длинномерных заготовок лигатуры, содержащей наночастицы TiC, была осуществлена последующая деформация литой заготовки. На рис. $6 a$ представлена отливка композита Al-TiC, а на рис. 6 - вид заготовки, на молоте прокованной на квадрат 10x10x250 мм. Полученные в результате ковки (прокатки) прутки не содержали видимых поверхностных дефектов и имели размеры и форму, пригодные для их практического использования в качестве модификатора.

\section{Обработка методами интенсивной пластической деформаџии}

Для получения Al-сплавов в субмикро- и нанокристаллическом состояниях были применены два метода интенсивной пластической деформации: ДКУП и КГД. Первый обеспечивал создание субмикрокристаллической (СМК) структуры с размером зерна от 200 до 500 нм уже после 1-2 циклов ДКУП [11-13], а второй - нанокристаллической (НК) структуры с размером зерна 35-100 нм [14, 15].

В термически неупрочняемом сплаве АМц (исходная микротвердость $\mathrm{H}_{\mathrm{V}}=450 \mathrm{MPa}$ ) процесс образования СМК-структуры носит цикличный характер и осуществляется либо фрагментацией, либо динамической рекристаллизацией [11]. Просвечивающая электронная микроскопия показала, что при $\mathrm{N} \leq 2, \mathrm{~V} \leq 300 \mathrm{~m} / \mathrm{s}$ образование СМК-структуры происходит путем фрагментации ячеек за счет изгиба кристаллической решетки и ротационных мод деформации. Образованная таким механизмом структура состоит из кристаллитов, разделенных большеугловыми неравновесными границами, содержащих скопления решёточных дислокаций. При $\mathrm{V} \geq 300 \mathrm{~m} / \mathrm{s}$ и $\mathrm{N} \geq 4$ формирование СМК-структуры есть результат протекания динамического возврата и динамической рекристаллизации по непрерывному механизму. По данным EBSD-

$$
-526-
$$




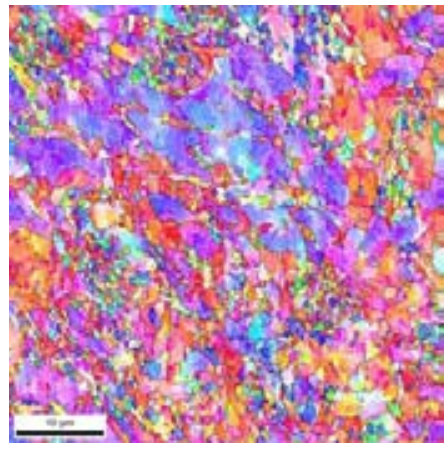

a

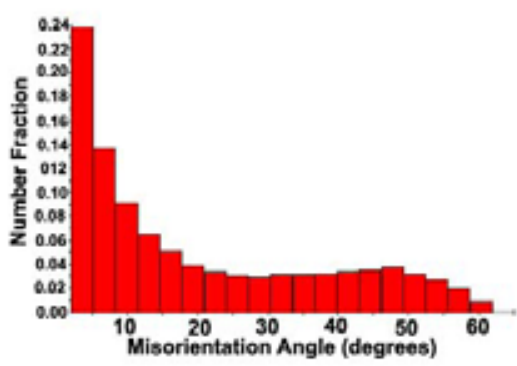

6

Рис. 7. Структура сплава АМц после ДКУП (V = $300 \mathrm{~m} / \mathrm{s}, \mathrm{N}=4)$ в обратно отражённых электронах СЭМ (а) и гистограмма распределения углов разориентировки кристаллитов (б)

анализа, СМК-структура в основном состоит из кристаллитов, разделенных большеугловыми границами, а средний размер кристаллитов составляет 600 нм (рис. 7).

В СМК-состоянии твердость материала по сравнению с отожженным крупнокристаллическим состоянием увеличилась в 2-2.5 раза. Образование СМК-структуры в объемных образцах положительным образом сказалось на их механических свойствах. Было установлено, что по сравнению с исходным отожженным состоянием значение временного сопротивления разрыву

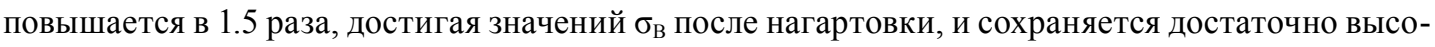
кая пластичность $(\delta=16 \%)[12]$.

Другой сплав - сплав В95 - является сложнолегированным алюминиевым сплавом, основу которого составляет пересыщенный $\alpha$-твердый раствор с микротвёрдостью $\mathrm{H}_{\mathrm{v}}=680 \mathrm{MPa}$. Установлено, что рост твёрдорастворного упрочнения усиливает фрагментацию и инициирует формирование более мелкой, чем в сплаве АМц, СМК-структуры (200 нм).

Согласно результатам ПЭМ после двух циклов ДКУП при $\mathrm{V}=150 \mathrm{~m} / \mathrm{s}$ наблюдается высокая плотность решеточных дислокаций и размытые неравновесные большеугловые границы, разделяющие отдельные кристаллиты с внутренним неоднородным контрастом. Все вышеперечисленные характеристики такой структуры свидетельствуют о том, что в этом сплаве механизмом релаксации упругой энергии является фрагментация. В отличие от сплава АМц с ростом числа циклов ДКУП напряженно-деформированное состояние сохраняется. Возможной причиной отсутствия признаков динамической рекристаллизации служит блокировка границ интерметаллидной фазой $\mathrm{MgZn}_{2}$ и алюминидами ПМ [13]. Учитывая высокую производительность метода ДКУП, а также возможность эффективного измельчения структуры и повышения прочностных характеристик объемных материалов, можно считать, что такой способ имеет большой потенциал для практического использования.

При изучении деформационного поведения бинарных и тройных Al-TM-сплавов при КГД были выявлены следующие закономерности [14, 15]. Установлено, что при КГД протекают три конкурирующие между собой процесса: фрагментация структурных составляющих, деформационное растворение алюминидов ТМ и образование пересыщенных Al твердых растворов.

$$
-527-
$$


Многоплановые исследования методами электронной микроскопии и рентгеновской дифракции показали, что после деформации кручением (e $=4,5-6,0 \mathrm{n}=3-5)$ в быстрозакалённых сплавах достигается предельный средний размер зерен, который в зависимости от состава материала колеблется от сотен до десятков нанометров. Так, в бинарных композициях минимальный средний размер кристаллитов составил 150 мкм, в тройном $\mathrm{Al}-\mathrm{Cr}-\mathrm{Zr}$ сплаве - 70 мкм, в $\mathrm{Al}-\mathrm{Mg}-\mathrm{Mn}$ сплавах, легированных $\mathrm{Zr},-60$ нм, а при добавлении $\mathrm{Sc}-35$ нм. Следовательно, повышение твердости основы путем дополнительного легирования тугоплавкими металлами стимулирует формирование наномасштабных элементов структуры [16]. Такое структурное состояние обеспечивает высокие значения твердости нанокристаллических (НК) материалов. Она достигает 1.8-2.5 GPa, что в 2.5-3 раза превышает микротвердость матрицы в быстрозакаленном состоянии и в 5 раз - в литом сплаве. Образовавшиеся в результате комплексной обработки (быстрой закалки и КГД) аномально пересыщенные ТМ твердые растворы на основе алюминия достаточно устойчивым в процессе деформационного цикла. Несмотря на наличие дефектов (неравновесных вакансий и дислокаций), они не подвержены распаду и рекристаллизации при низкотемпературных обработках.

Проведено сравнение и выявлены особенности деформационного поведения метастабильных и стабильных алюминидов ТМ, находящихся в окружении пластичной Al-матрицы. Установлено, что кинетика деформационного растворения алюминидов зависит от их размеров и типа кристаллической решетки. Быстрее всего при $\mathrm{n}=1(\mathrm{e}=4.5)$ растворяются метастабильные фазы с кубической решеткой $\left(\mathrm{Al}_{3} \mathrm{Zr}, \mathrm{Al}_{3} \mathrm{Sc}\right)$, несколько хуже, при $\mathrm{n}=2-5$ (е = 5.1-5.8), - интерметаллиды с орторомбической решеткой $\left(\mathrm{Al}_{6} \mathrm{Fe}\right)$ и труднее всего при $\mathrm{n}>5$ (e>5.8) - кристаллы с моноклинной решеткой $\left(\mathrm{Al}_{7} \mathrm{Cr}\right)$. Методами рентгеновского анализа обнаружено, что комплексная обработка сплавов в жидком и твердом состояниях (перегрев, быстрая закалка расплава и КГД) повышает степень пересыщения Al твердого раствора тугоплавкими металлами относительно равновесного состояния в 3-10 раз.

Изучена последовательность постдеформационных явлений (возврата, старения и рекристаллизации) в быстрозакалённых сплавах с $\mathrm{Cr}, \mathrm{Zr}$ и Fe при низкотемпературном отжиге. Установлено, что процесс старения «накладывается» на процесс возврата и за счет эффекта дисперсионного твердения компенсирует потерю упрочнения материала, которая неизбежна при релаксации внутренних напряжений, связанной с нагревом. Определена температурная граница стабильности НК-состояния, которая для быстрозакристаллизованных сплавов Аl-ТМ составляет $\sim 0.5 \mathrm{~T}_{\text {плл }}$ что на 0.1-0.2 $\mathrm{T}_{\text {пл }}$ выше, чем для литых промышленных алюминиевых сплавов. Высокая термическая устойчивость таких наноструктурных сплавов обусловлена блокировкой большеугловых границ зёрен алюминидами, которые образуются при старении или сохраняются при КГд.

Результаты, полученные на модельных Аl-ПМ-сплавах, были дополнены исследованиями фазовых и структурных превращений при кручении промышленного сплава В95. Образцы были вырезаны из термообработанного по режиму Т1 и отожженного прутка и имели субзеренную структуру $\mathrm{Al}$-матрицы с интерметаллидами $\mathrm{MgZn}_{2}$ и алюминидами $\mathrm{TM}(\mathrm{Mn}, \mathrm{Fe}$, $\mathrm{Cr})$. Исследования показали, что при КГД с е $=5.5-6.4$ формируется НК состояние с размером зерен 55-80 нм соответственно. В процессе КГД наблюдается растворение интерметаллидов стабильной фазы $\mathrm{MgZn}_{2}$ с последующим выделением из пересыщенного Al твердого раство- 
ра дисперсной метастабильной упрочняющей фазы ү'. Наличие в структуре алюминидов ТМ препятствует процессу динамической рекристаллизации, и образование НК структуры происходит сдвиговым и ротационным механизмами деформации. С ростом степени деформации $e>6.4$ наблюдается деформационное растворение алюминидов ТМ, в материале активизируется процесс роста зерен, и их средний размер увеличивается до 115 нм.

\section{Заключение}

Из анализа представленных экспериментальных данных следует, что, воздействуя на жидкие и твердые Al-сплавы с TM, можно измельчить зеренную структуру в широком диапазоне размеров, а именно от десятков микрон до десятков нанометров. Для получения в литых сплавах микроструктуры с зерном 5-10 мкм целесообразна комплексная обработка расплава, заключающаяся в его нагреве до определенной по политерме вязкости расплава температуры, выдержке и быстрой закалке со скоростью не менее $10^{3}{ }^{\circ} \mathrm{C} / \mathrm{s}$. Показано, что для создания СМК-структуры в объемных образцах из алюминиевых промышленных сплавов эффективно применять метод ДКУП. Установлено, что нанокристаллическое состояние в бинарных и легированных алюминиевых сплавах достигается только при кручении под высоким квазигидростатическим давлением.

Предложены технологии получения лигатурных сплавов, обладающих высокой легирующей и модифицирующей способностью, за счёт формирования в их структуре дисперсных метастабильных алюминидов циркония или титана, а также наночастиц карбида титана.

Работа выполнена по плановой теме ИФМ УрО РАН (иифр “Структура», № zoc. per. 01201064335).

Автор выражает благодарность своим соавторам В.В. Астафьеву, А.Н. Петровой, И.Г. Ширинкиной, Т.И. Яблонских, В.В. Майкову, П.В. Котенкову за помощь в работе.

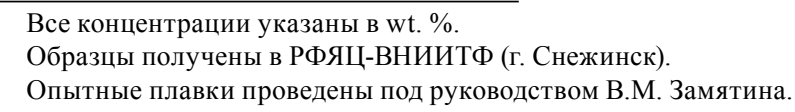

\section{Список литературы}

[1] Елагин В.И. Легирование деформируемых алюминиевых сплавов переходными металлами. М.: Металлургия, 1975. 248 с.

[2] Добаткин В.И., Елагин В.И. Гранулируемые алюминиевые сплавы. М.: Металлургия. $1981,176 \mathrm{c}$.

[3] Напалков В.И., Бондарев В.И. Лигатуры для производства алюминиевых и магниевых сплавов. М.: Металлургия, 1983. $159 \mathrm{c.}$

[4] Бродова И.Г., Попель П.С., Барбин Н.М., Ватолин Н.А. Исходные расплавы как основа формирования структуры и свойств алюминиевых сплавов. Екатеринбург: УрО РАН, 2005. $369 \mathrm{c}$.

[5] Valiev R.Z., Estrin Yu., Horita Z. et al // JOM. 2006. Vol. 58(4). P. 33.

[6] Murashkin M.Yu., Markushev M.V., Ivanisenko Yu.V., Valiev R.Z. // J. Solid State Phenomena. 2006. Vol. 114. P. 91. 
[7] Шорохов Е.В., Жгилев И.Н., Валиев Р.3. Пат. 2283717 РФ (2004) / Б. И. 2006. № 26.

[8] Бродова И.Г., Замятин В.М., Ермаков А.Е. и др. // Проблемы и перспективы развития металлургии и машиностроения с использованием завершенных фундаментальных исследований и НИОКР: Труды НТК. Екатеринбург: УрО РАН, 2011. Т. 1. С. 231.

[9] Бродова И.Г., Уймин М.А., Астафьев В.В. и др. // Письма о материалах. 2013. Т. 3. С. 91.

[10] Pastukhov E.A., Popova E.A., Bodrova L.E. et. al. // Расплавы. 1998. № 3. С. 7.

[11] Бродова И.Г., Шорохов Е.В., Ширинкина И.Г. и др. // Физика металлов и металловедение. 2008. Т. 105. № 6. С. 630.

[12] Петрова А.Н., Бродова И.Г., Ширинкина И.Г., Насонов П.А., Шорохов Е.В. Особенности ультразернистого и нанокристаллического состояний в сплаве АМц, полученных при интенсивных воздействиях // Письма о материалах. 2013. Т. 3. С. 126.

[13] Бродова И.Г., Ширинкина И.Г., Петрова А.Н и др. // Перспективные материалы. 2011. № 12. C. 60 .

[14] Бродова И.Г., Ширинкина И.Г., Петрова А.Н. // Письма о материалах. 2011. Т. 1. №1. C. 32 .

[15] Бродова И.Г., Ширинкина И.Г., Антонова О.В. // Физика металлов и металловедение. 2007. T.104. С. 294-301.

[16] Бродова И.Г., Ширинкина И.Г. // Деформация и разрушение материалов. 2009. № 7. C. 21. 